This PDF is a selection from a published volume from the National Bureau of Economic Research

Volume Title: Social Security Programs and Retirement around the World: The Relationship to Youth Employment

Volume Author/Editor: Jonathan Gruber and David A. Wise, editors

Volume Publisher: University of Chicago Press

Volume ISBN: 978-0-226-30948-4; 0-226-30948-7

Volume URL: http://www.nber.org/books/grub08-1

Conference Date:

Publication Date: February 2010

Chapter Title: Early Retirement and Employment of the Young in the Netherlands

Chapter Author: Arie Kapteyn, Klaas de Vos, Adriaan Kalwij

Chapter URL: http://www.nber.org/chapters/c8258

Chapter pages in book: (243 - 259) 


\title{
Early Retirement and Employment of the Young in the Netherlands
}

\author{
Arie Kapteyn, Klaas de Vos, and Adriaan Kalwij
}

\subsection{Introduction}

Previous papers on the National Bureau of Economic Research International Social Security Project focused on the incentives to retire, the effects of possible reforms, and the well-being of the elderly. In this chapter, we return to one of the factors underlying the emergence of widespread early retirement opportunities: the desire to create or preserve jobs for the young. When early retirement was first proposed in the late seventies in the Netherlands, unemployment soared, and the idea was that by sending elderly workers into early retirement, younger workers would be able to keep their jobs. Early retirement was considered to be a win-win solution: the elderly who had worked hard during the reconstruction period after World War II could take up a well-deserved early retirement pension, while the young who were at risk of becoming a "lost generation" could take their places in the labor market. The first trade union plan (1975) proposing early retirement was in fact called "Jong voor Oud" ("Young for Old"). Next to the introduction of early retirement programs for elderly workers in most sectors in the late seventies and early eighties, employers and trade unions also colluded to send older workers into disability or unemployment, with employers often supplementing the already generous statutory benefits until the social security eligibility age (and mandatory retirement age) of sixty-five was reached.

All in all, the labor force participation (LFP) of the (male) elderly shows a considerable decrease between the late seventies and late nineties, after which most early retirement programs were scaled down because they were fast

Arie Kapteyn is a senior economist at RAND and director of RAND Labor and Population. Klaas de Vos is a senior researcher in the Quantitative Analysis department of CentERdata at Tilburg University. Adriaan Kalwij is a researcher at the Utrecht School of Economics. 
becoming financially unsustainable, and the government finally appeared to succeed in effectively restricting access to unemployment and disability benefits.

In this chapter, we try to answer the question, did early retirement of the elderly from the labor force (be it via early retirement programs or alternative routes such as disability and unemployment benefits) indeed create jobs for the young? We start by providing a brief history of the main benefit schemes related to retirement: early retirement, disability, social security, and occupational pensions. Next, we present some graphical evidence on the relationship between employment and unemployment of the young and labor force participation of the old. After that, we present regressions explaining labor market status of the young as a function employment of elderly. Next, we investigate the time series properties of these variables and of a few indicators of retirement incentives. We will find that the incentive indicators we have constructed are plausibly caused by the employment of the young, confirming the view that these incentives were indeed introduced to alleviate the youth unemployment problem. It also implies that these variables cannot be used as instruments in regressions to explain youth employment as a function of employment of the elderly. However, we will find variables that do seem to be predetermined for labor force participation of the elderly. This allows us to estimate the effect of labor force participation of the elderly on employment of younger age groups in the labor markets, using instrumental variables. Generally, the relations we obtain suggest complementarity between labor force participation of the elderly and employment of the younger age groups. Thus, if anything, attempts to reduce unemployment via strong incentives for retirement most likely have aggravated the problem rather than alleviating it.

\subsection{The Early Retirement Debate and Other Exit Routes from the Labor Market in the Netherlands}

The first plan for the introduction of early retirement was proposed by a board member of the Netherlands Catholic Trade Union, Toon Riemen, in 1975. Mr. Riemen's plan was called "Young for Old" and had as its primary purpose to reduce youth unemployment. ${ }^{1}$ The plan aimed to kill two birds with one stone. As he put it in a recent interview: "Since the 1973 oil crisis, there was a big problem with youth unemployment. At the same time you saw elderly employees who were at the end of their tether. Then you start brainstorming, can't we think of a plan to solve that." The essence of the plan was an old person out and a young person in (VPRO 2004).

The Minister of Social Affairs decided to set up a commission that was

1. The information about the history of the early retirement debate is partly taken from VPRO (2004). See also Van Oorschot (2007). 
to advise on the merits of the early retirement (ER) plan. The commission, headed by a board member of the Unilever pension fund, Van Tets, advised against the idea. The commission felt that the plan's potential for solving the youth unemployment problem was illusory. Nevertheless, the Minister of Social Affairs, Boersma, decided to start an experiment in two sectors: education and construction. As of December 1, 1976, and April 1, 1977, respectively, employees in these sectors had the possibility to retire at the age of sixty-three or sixty-four, instead of the statutory retirement age of sixty-five.

Soon, the ER plans were extended to other sectors. In February 1975, the Minister of Social Affairs avoided an impending strike in Rotterdam harbor by offering employees an ER plan at the government's expense.

The ER plans proved to be very popular with both employees and employers. The ER was financially very attractive to employees. The before-tax replacement rate usually was on the order of 80 or 90 percent, and since no payroll taxes were levied on the retired, the net replacement rate could be very close to 100 percent. Moreover, one kept accumulating pension rights as if one was still employed.

Employers liked the ER plans because it made it easy to reduce the labor force during the economic downturn. Typically, employees would be eligible if they had worked for the same company for at least ten years.

In 1980, the ER experiment was codified into law and in the following years was incorporated in many collective agreements.

The financing of ER was pay-as-you-go. As such, it provided a classic example of a transfer between generations. The employed paid for the ER of the older generation by means of a special payroll tax, while the retired only reaped the benefits.

Not surprisingly, the take-up of ER was very large. For instance, in the first year more than 50 percent of the age-eligible construction workers decided to retire early, twice as many as anticipated by the government. In later years, take-up got close to 100 percent.

There is some debate about whether the spread of ER has contributed to the goal of reducing youth unemployment. The originator of the "Young for Old," Toon Riemen, does not think so: "Nothing is left of the original goal" (VPRO 2004).

\subsubsection{Disability Insurance}

Even before ER schemes were introduced, employees could retire before the standard retirement age of sixty-five. The most frequently used exit route was Disability Insurance (DI). Although various work disability laws had been in existence since the early twentieth century, a comprehensive DI law was introduced in 1967, covering all employees (but not self-employed). Interestingly, the law passed parliament without any nay vote. Any person with a whole of partial work disability was entitled to a benefit equal to 80 
percent of previous earnings. In after-tax terms, this might be equivalent to 90 percent. There was no time limit to the benefit period, so in principle, one could expect to receive benefits until the statutory retirement age of sixtyfive. Moreover, while drawing DI benefits, one often also kept accumulating pension rights, while one no longer had to pay the pension premium that workers pay.

The number of beneficiaries showed an explosive growth, as illustrated in figure 8.1. As with the later ER schemes, take-up was much higher than anticipated. The government had estimated that the maximum number of DI beneficiaries would be 200,000, but in 1976 the number of beneficiaries had already reached 500,000. As with ER, the scheme was popular among both employees and employers. For employees, it was an attractive exit route, as may be clear from the description of the financial aspects of the scheme. For employers, the scheme had the advantage of a relatively easy way to terminate employees, which under Dutch law would be complicated and costly otherwise.

The dramatic increase in the number of DI beneficiaries led to obvious budgetary problems, which triggered a number of reforms, all aimed at a reduction of the DI rolls. In 1985, despite massive protests, the benefit was reduced from 80 percent of previous earnings to 70 percent. In 1987, DI was no longer possible for individuals who were previously (fully or partially) unemployed. One can see from figure 8.1 that these changes did not have much of a visible effect on the growth of the DI rolls. In 1991, the length of the benefit period was reduced for persons who at that time were less than fifty years of age. Figure 8.1 suggests that this may have had some effect on the number of DI recipients in later years. In 1998, partial experience rating was introduced. In 2004, DI beneficiaries younger than fifty had to undergo strict medical reexaminations. Finally, in 2006, a new DI law replaced the old one. Under the new law, during the first two years after one becomes disabled, wages continue to be paid. After two years a determination takes place of whether one is permanently disabled for at least 80 percent. In that case DI benefits are 75 percent of a worker's previous wages until the age of sixty-five. Work limitations that are deemed to be less than 35 percent do not entitle a worker to DI benefits. Between 35 percent and 80 percent one receives a DI benefit equal to 70 percent of the earnings loss for a maximum period of thirty-eight months. After that, the benefit depends on earnings loss and the extent to which one uses the remaining earnings capacity; see, for instance, Van Oorschot (2007).

\subsubsection{Social Security}

The social security (SS) act was passed in $1957 .{ }^{2}$ The system was extremely simple. Any man or unmarried woman was entitled to a fixed amount, in-

2. The information in this section has been derived from SVB (2007). 


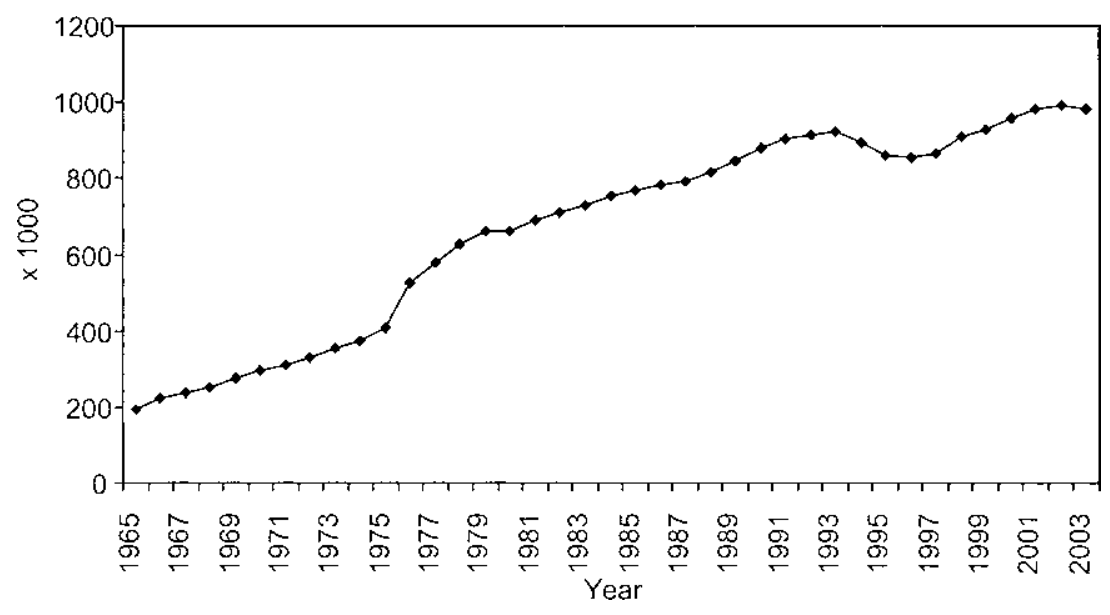

Fig. 8.1 Number of disability insurance benefits

dependent of work history. Married women were not entitled to their own benefit. Only in the eighties did the unequal treatment of men and women come to an end so that also women had their own independent entitlement to an SS benefit. As of 1979, the level of benefits is linked to the aftertax minimum wage. In later changes, benefits for younger partners of SS recipients were introduced. This will now be abolished by 2015 . There is no earnings test for SS, so one can receive SS while being gainfully employed. Figure 8.2 shows the evolution of the level of SS benefits for both married and unmarried individuals since 1975 . The figure shows steady growth of the benefit level until about 1979. The fact that after 1979 the benefit level falls in real terms is due to the linkage with after-tax minimum wages. The after-tax minimum wage also determines the level of welfare benefits. When in the early eighties the economy entered into a recession and government deficits ballooned, the government reacted by cutting the minimum wage, welfare benefits, and as a result, also SS benefits. Later fluctuations in the level of SS benefits mainly reflect economic conditions and the state of the government budget, which influenced minimum wages, welfare benefits, and through the linkage, also SS benefits. Changes in the tax system were another important determinant.

\subsubsection{Private Pensions}

The bulk of private pensions in the Netherlands consist of occupational pensions. Typically, employment for a certain company or in a certain sector implies mandatory participation in a pension plan. Pensions tend to be of the defined benefit type with benefits depending on final pay or average pay. Usually, a full pension will amount to 70 percent of either full or average 


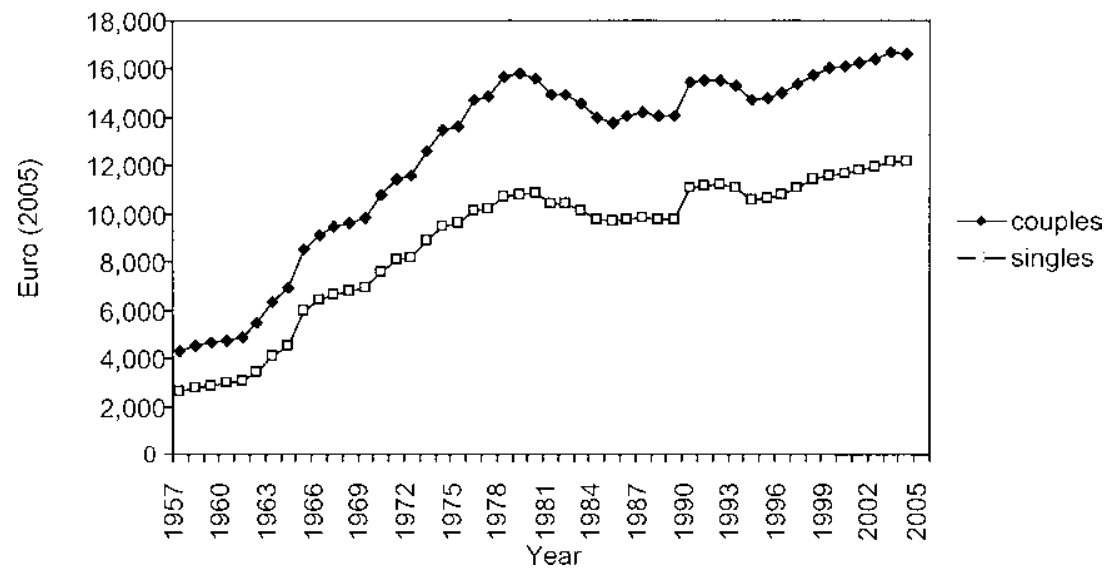

Fig. 8.2 Social security benefits before taxes

pay if one has contributed for forty years. For each year less, one loses 1.75 percentage points. Benefits are usually indexed by the wage index. Since the early 2000s, many pension schemes have moved from final pay to average pay and wage indexation has become less automatic. In principle pensions are portable if one changes jobs. The associated pension liabilities are moved from one pension fund to the next.

\subsection{Measures of Employment}

Based on the Organization for Economic Cooperation and Development (OECD) employment data, we consider the following measures of employment:

- LFP and employment (old, fifty-five to sixty-four) as fraction of total population

- LFP and employment (old fifty-five to sixty-four, male), as fraction of total population

- LFP and employment (old, fifty-five to sixty-four, female), as fraction of total population

- Unemployment (young, twenty to twenty-four), as fraction of total population

- Unemployment (prime age, twenty-five to fifty-four), as fraction of total population

- LFP and employment (young, twenty to twenty-four), as fraction of total population

- LFP and employment (prime age, twenty-five to fifty-four), as fraction of total population 
From Statistics Netherlands, we obtain the percentage of persons twenty to twenty-four that are in school. Also from Statistics Netherlands, we use data on gross domestic product (GDP), GDP per capita, share of manufacturing in the economy, and the statutory minimum wage. Finally, we construct two measures of incentives to retire. One is a macroindicator of social security wealth and the other one is an indicator of peak value. The construction of these two variables is described in the appendix.

For elderly males and females, employment and labor force participation are very close. For most of the period under consideration, elderly unemployed were receiving benefits without having the obligation to seek a job. This effectively removed them from the labor market.

\subsection{Graphical Evidence}

Figures 8.3 through 8.5 show the evolution of the main variables of interest between 1971 and 2005. Figure 8.3 shows the LFP of older persons fifty-five to sixty-four, the LFP of young persons twenty to twenty-four, and the unemployment rate of young persons twenty to twenty-four. Figure 8.3 presents time series for the LFP of the elderly and the unemployment of the two younger age groups (twenty to twenty-four and twenty-five to fifty-four) and figure 8.4 presents time series for the LFP of the elderly and

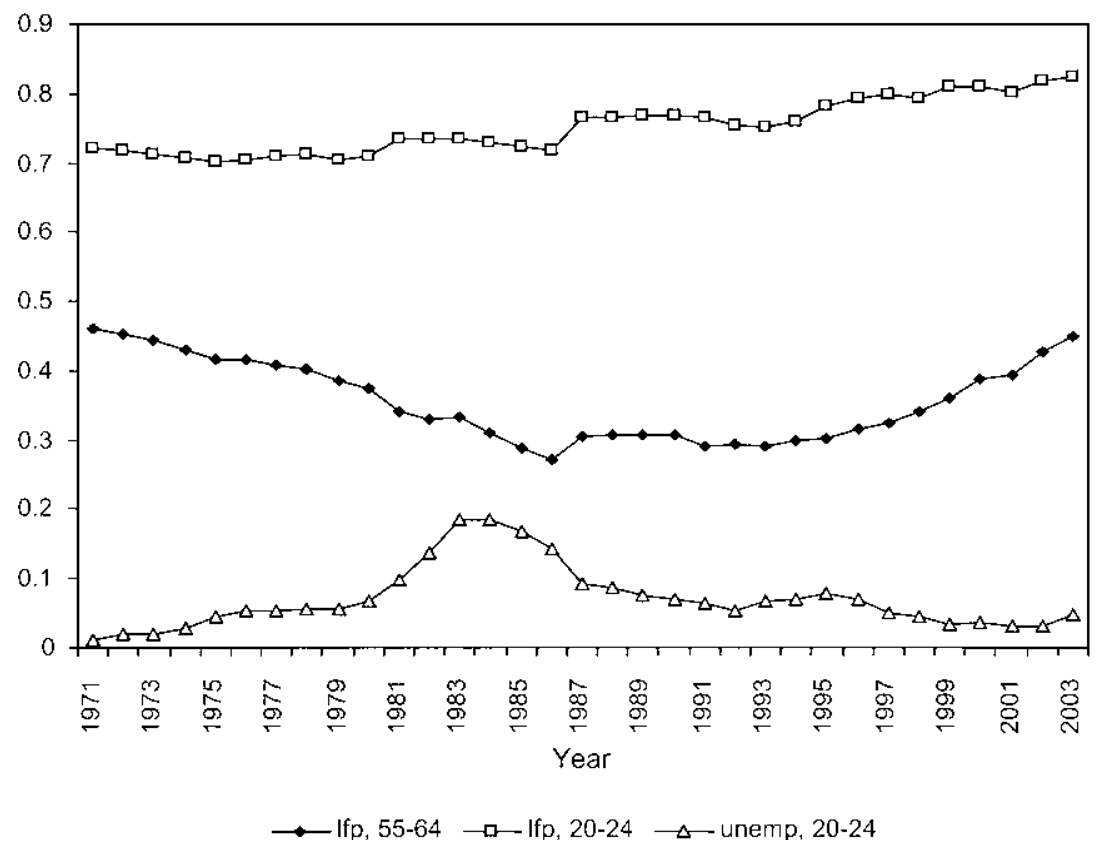

Fig. 8.3 Labor force participation (old and young) and unemployment (young) 


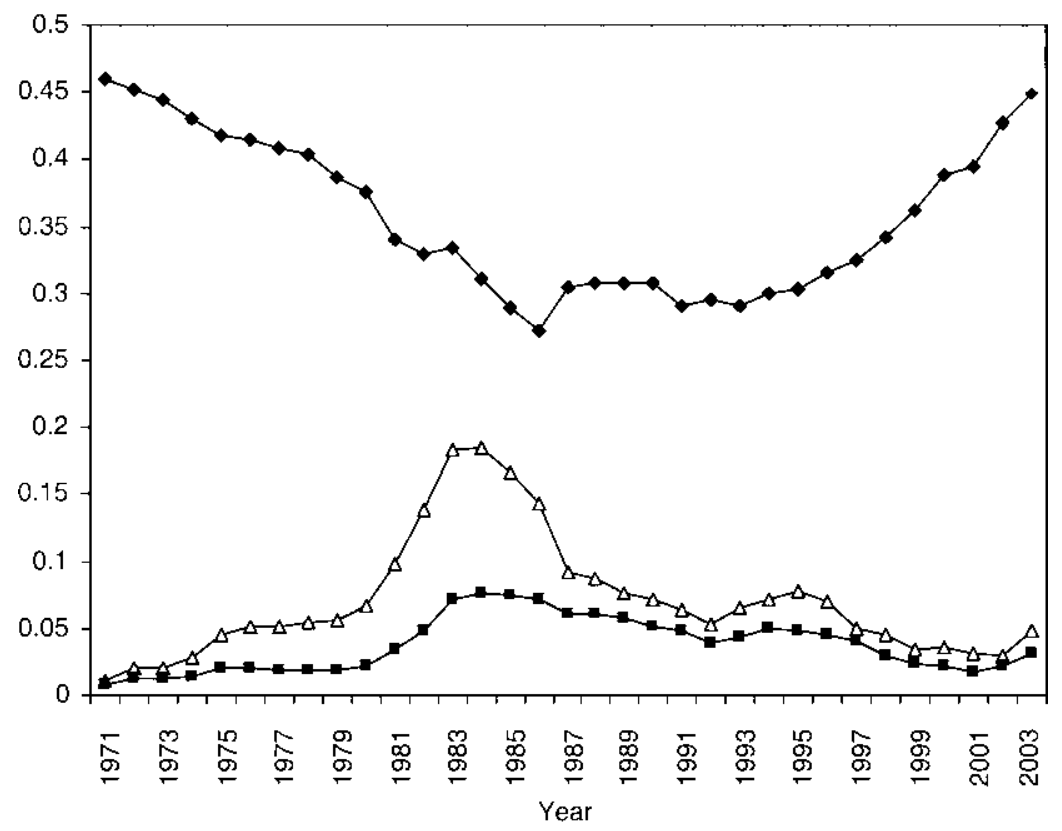

$\rightarrow$ Ifp, 55-64 $\rightarrow$ - unemp, 20-24 $\rightarrow$ unemp, 25-54

Fig. 8.4 Labor force participation (old) and unemployment (young and prime age)

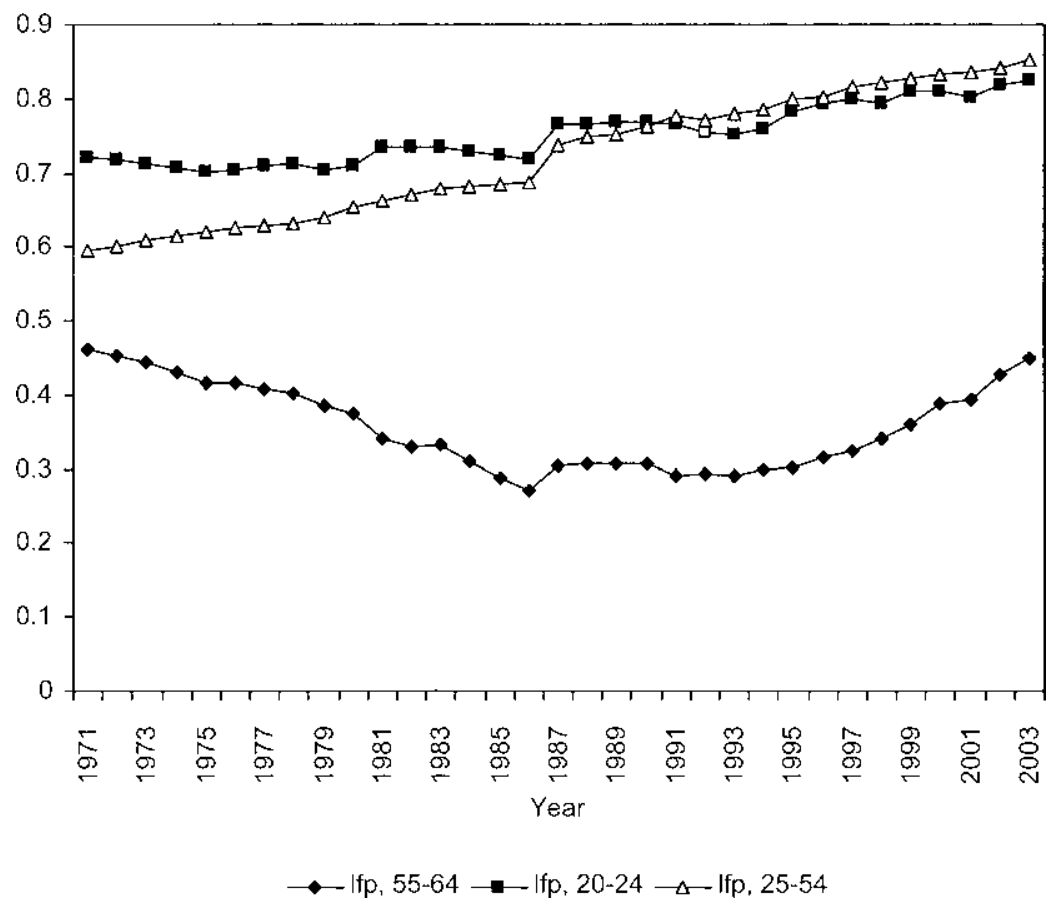

Fig. 8.5 Labor force participation (old, young, and prime age) 
the two younger age groups. Taken on face value, the graphs do not provide much support for the idea that reducing employment of the elderly reduces unemployment for the younger age groups. If anything, unemployment of the younger age groups seems to go up while the employment of the elderly is low. Apart from obvious economic reasons why this may be so (such as complementarity of employment of different age groups), this may also simply be an artifact. If unemployment of all three age groups is correlated, and if the elderly unemployed leave the labor market, then we expect the pattern shown in figure 8.4.

A complicating factor in studying the relationship between the LFP of the elderly and employment and unemployment of the young is the fact that the LFP of the elderly males and females shows different trends during the first half of the period (1971 to 1987). See figure 8.6. Most likely this reflects a cohort effect whereby younger cohorts of females exhibit a higher LFP than older cohorts. The flat curve for female LFP during the first half of the period may therefore be the net result of an increase in the retirement hazard (just as for males) and at the same time a larger proportion working of younger cohorts. During the second half of the period, both female and male LFP are growing, but of course it still remains impossible to say how

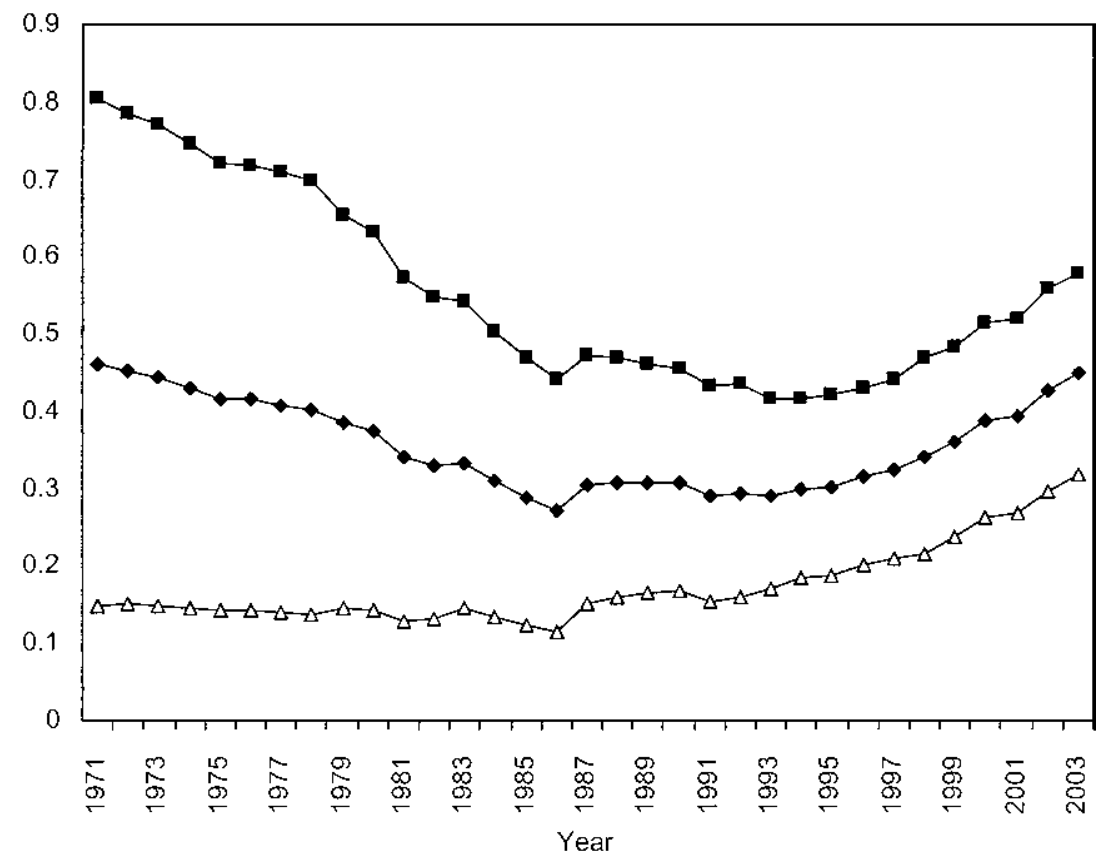

$\rightarrow$ Ifp, 55-64 $\rightarrow-$ Ifp, 55-64, m $\rightarrow-$ Ifp, 55-64, f

Fig. 8.6 Labor force participation (old) by gender 
much of the growth in female LFP is a cohort effect and how much reflects a lower retirement hazard. Since cohort effects are less likely to play a major role in male LFP, we will often concentrate on male LFP among the elderly, rather than total elderly LFP.

\subsection{Direct Effect of Elderly LFP on the Young}

Before turning to a more systematic exploration of the relation between elderly LFP and employment and unemployment of younger age groups, we first consider simple regressions where we regress outcomes for younger age groups on elderly LFP.

Tables 8.1 and 8.2 show the results of a number of regressions in which the dependent variable is either employment, unemployment, or the percentage in school. We show the coefficients of employment of the elderly; regressions are done in levels, in levels with a three-year lag on elderly employment, in five-year differences, and in five-lear $\log$ differences (i.e., of the form: $\ln X[t]-\ln X[t-5])$. Moreover, regressions are repeated with and without other covariates (which are not reported in the table). The other covariates include GDP per capita, the growth in GDP per capita, and the share of manufacturing in the economy.

If early retirement of the elderly age group were to have a beneficial effect on the employment of the younger age group, then the effect of elderly employment on employment of younger age groups should be negative, while on unemployment it should be positive. When elderly employment decreases, employment of the young should increase, while unemployment should decrease.

In specifications without other covariates we find for the young (twenty to twenty-four) and the prime aged (twenty-five to fifty-four) that the effects of elderly employment on unemployment are statistically significant but with the "wrong" sign. That is, lower labor force participation of the elderly seems to generate higher unemployment of the young. There are various possible explanations for this. One explanation is the existence of complementarities between employment of different age groups. A second explanation is endogeneity of policies: if unemployment soars, policymakers may increase incentives for elderly workers to retire. We will return to this possibility later.

When regressing employment of the younger age groups, the picture is a little more mixed. The effect of employment of the elderly on employment of the young tends to be positive or insignificantly negative (in the case where we use a three-year lag).

Once covariates are introduced, more coefficients become insignificant and sometimes change sign. In this case, regressions of employment in the prime age group on employment of the elderly suggest a potential beneficial effect of early retirement of the elderly on employment of prime aged 


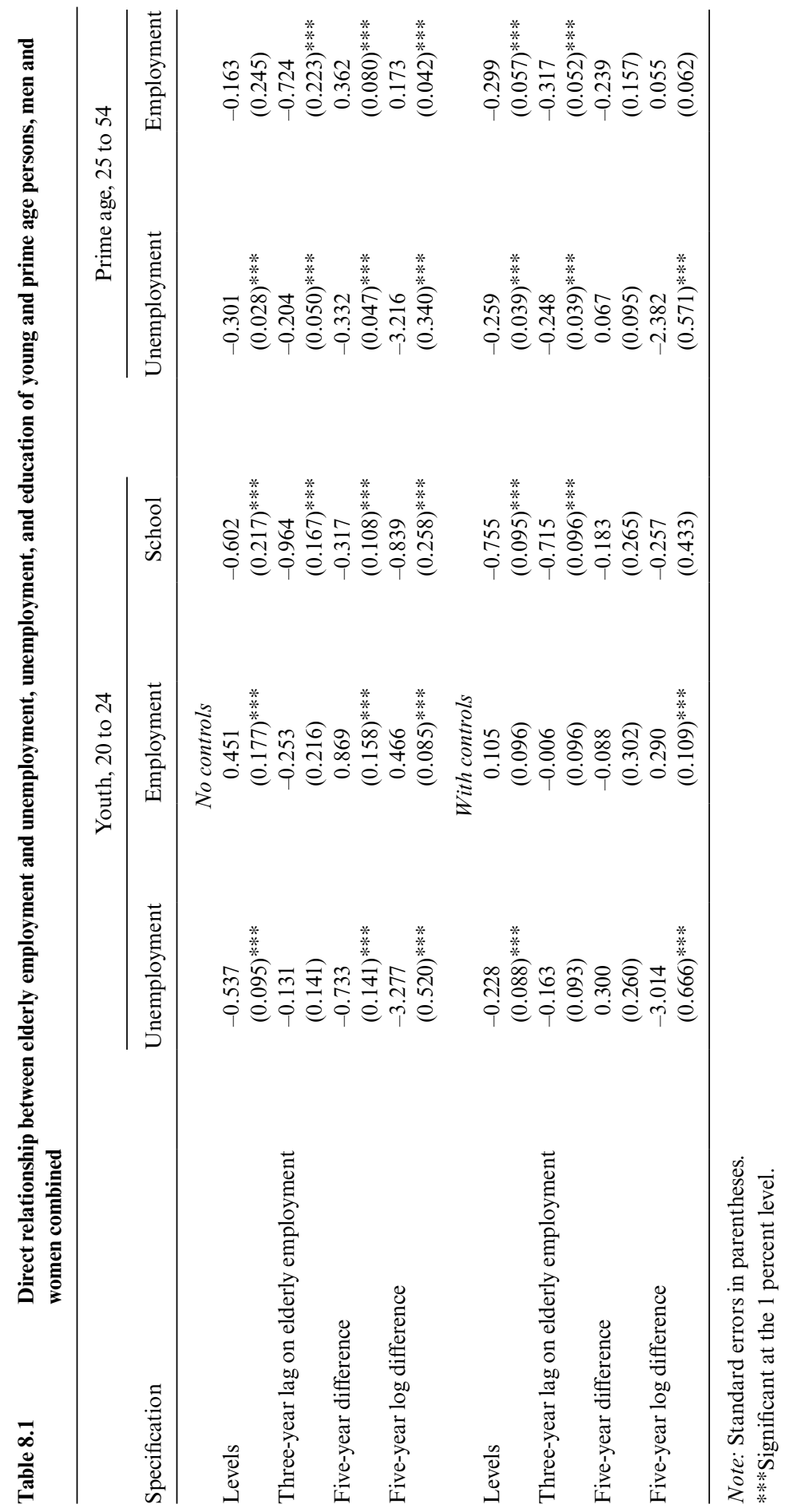




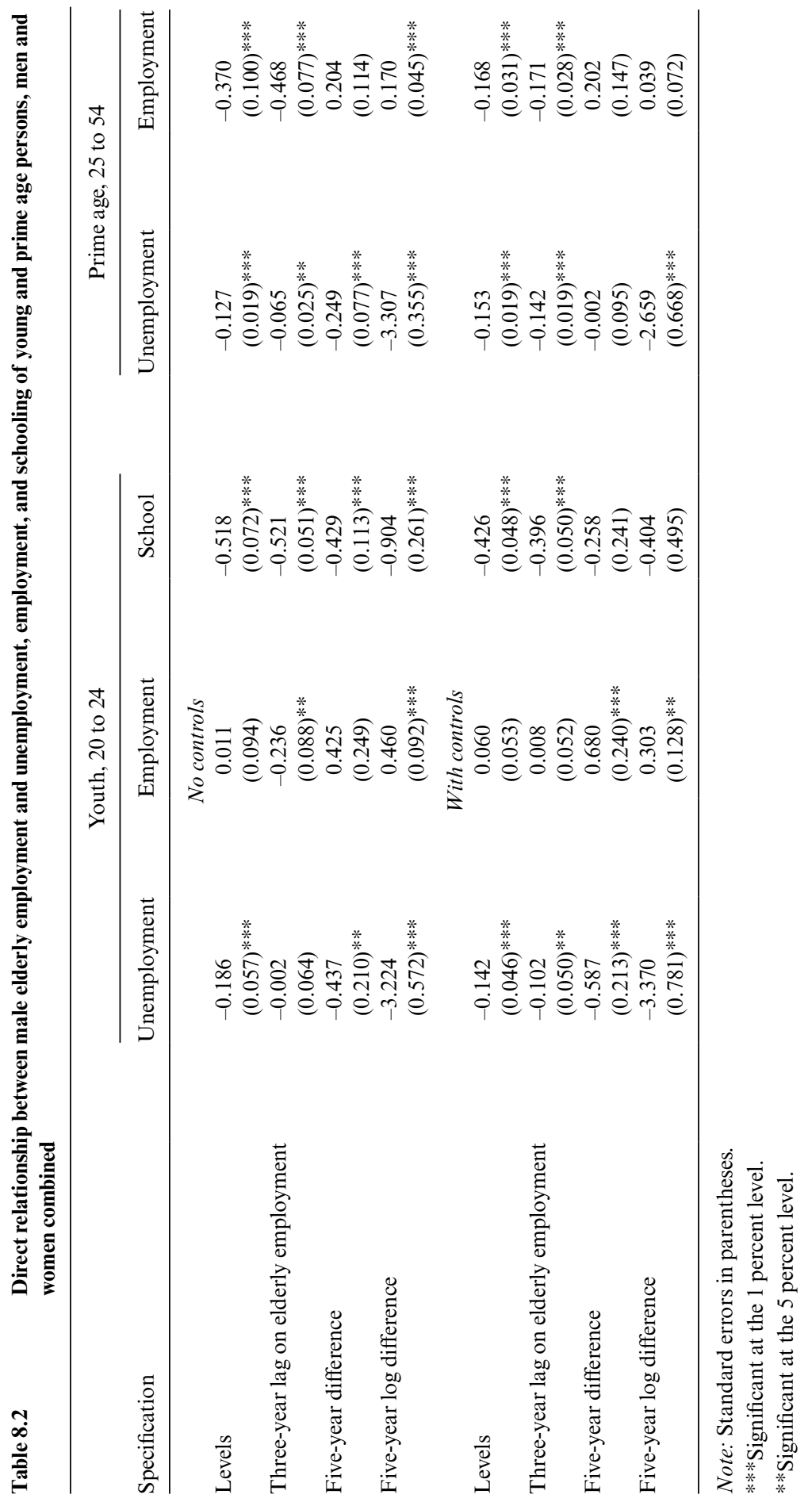


workers, both for employment of the elderly and employment of the elderly with a three-year lag. However, these significant coefficients disappear once a trend term is included. In sum, the regressions so far provide little evidence that inducing elderly workers to retire will alleviate unemployment of younger age groups.

For good measure, table 8.2 gives the results when we use employment of elderly males as an explanatory variable, in an attempt to reduce the possibly confounding effects of cohort differences between age categories. By and large the conclusion does not change, with most significant coefficients suggesting complementarity between employment of different age groups or becoming insignificant once a trend term is included.

It is striking to see that in all specifications elderly employment seems to have a negative effect on the proportion of the twenty to twenty-four age group in school. By and large the signs of the various coefficients of the school variable are the same as for the unemployment variable. This suggests that when job opportunities become scarce, young people are more likely to stay in school or to return to school. We also note that when we add a number of covariates, and in particular a time trend, many of the coefficients become insignificant.

\subsection{Causality Tests on Differenced Variables}

Dickey Fuller tests suggest that all variables of interest in the analysis have unit roots. Hence, the subsequent analysis is in terms of first differenced variables. Table 8.3 presents an overview of Granger causality tests for the various variables of interest. ${ }^{3}$ We note that the two incentive variables (wbar and Wminpv) are Granger caused at least by employment of the young. ${ }^{4}$ This confirms the historical description in section 8.2 that worsening employment of the young was a major factor in creating incentives for the elderly to leave the labor force. It also means that regressing youth unemployment on the incentive variables cannot reasonably be interpreted in a causal way. Employment of elderly males also appears to be Granger caused by youth employment.

The GDP per capita does not seem to be Granger caused by any of the other variables (although jointly they have a significant effect). The same is true for the percent of twenty to twenty-four in school (although that is Granger caused by GDP per capita). Based on these outcomes, we will use lagged values of GDP per capita and of percent of twenty to twenty-four in school as instruments in a regression of youth employment (and unemployment) on employment of the elderly.

3. The maximum number of lags used in the test is equal to two. Model selection criteria for choosing the number of lags favored from one to four lags, with relatively minor changes when the number of lags increased from two to four.

4. See the appendix for a description of the construction of these variables. 
Table 8.3

Granger causality tests

\begin{tabular}{|c|c|c|c|c|}
\hline Equation & Excluded & chi2 & df & Prob $>$ chi 2 \\
\hline \multirow[t]{8}{*}{ Employment (youth) } & School (youth) & 28.911 & 2 & 0 \\
\hline & Employment (prime age) & 23.983 & 2 & 0 \\
\hline & Employment (elderly males) & 2.9919 & 2 & 0.224 \\
\hline & Minimum wage & 7.6467 & 2 & 0.022 \\
\hline & GDP per capita & 2.2315 & 2 & 0.328 \\
\hline & Wbar & 10.709 & 2 & 0.005 \\
\hline & Wminpv & 5.6097 & 2 & 0.061 \\
\hline & All & 71.332 & 14 & 0 \\
\hline \multirow[t]{8}{*}{ School (youth) } & Employment (youth) & 3.2844 & 2 & 0.194 \\
\hline & Employment (prime age) & 5.8738 & 2 & 0.053 \\
\hline & Employment (elderly males) & 1.806 & 2 & 0.405 \\
\hline & Minimum wage & 3.8917 & 2 & 0.143 \\
\hline & GDP per capita & 11.046 & 2 & 0.004 \\
\hline & Wbar & 0.9598 & 2 & 0.619 \\
\hline & Wminpv & 1.8559 & 2 & 0.395 \\
\hline & All & 21.294 & 14 & 0.094 \\
\hline \multirow[t]{8}{*}{ Employment (prime age) } & Employment (youth) & 62.752 & 2 & 0 \\
\hline & School (youth) & 43.08 & 2 & 0 \\
\hline & Employment (elderly males) & 16.301 & 2 & 0 \\
\hline & Minimum wage & 16.97 & 2 & 0 \\
\hline & GDP per capita & 9.0657 & 2 & 0.011 \\
\hline & Wbar & 17.017 & 2 & 0 \\
\hline & Wminpv & 5.3358 & 2 & 0.069 \\
\hline & All & 184.74 & 14 & 0 \\
\hline \multirow[t]{8}{*}{ Employment (elderly males) } & Employment (youth) & 22.585 & 2 & 0 \\
\hline & School (youth) & 4.3938 & 2 & 0.111 \\
\hline & Employment (prime age) & 14.617 & 2 & 0.001 \\
\hline & Minimum wage & 14.913 & 2 & 0.001 \\
\hline & GDP per capita & 1.8118 & 2 & 0.404 \\
\hline & Wbar & 7.3343 & 2 & 0.026 \\
\hline & Wminpv & 4.6874 & 2 & 0.096 \\
\hline & All & 67.96 & 14 & 0 \\
\hline \multirow[t]{8}{*}{ Minimum wage } & Employment (youth) & 21.025 & 2 & 0 \\
\hline & School (youth) & 3.2539 & 2 & 0.197 \\
\hline & Employment (prime age) & 20.69 & 2 & 0 \\
\hline & Employment (elderly males) & 3.5881 & 2 & 0.166 \\
\hline & GDP per capita & 7.14 & 2 & 0.028 \\
\hline & Wbar & 33.363 & 2 & 0 \\
\hline & Wminpv & 22.309 & 2 & 0 \\
\hline & All & 155.06 & 14 & 0 \\
\hline \multirow[t]{8}{*}{ GDP per capita } & Employment (youth) & 3.0733 & 2 & 0.215 \\
\hline & School (youth) & 1.7618 & 2 & 0.414 \\
\hline & Employment (prime age) & 5.4397 & 2 & 0.066 \\
\hline & Employment (elderly males) & 5.2948 & 2 & 0.071 \\
\hline & Minimum wage & 2.8439 & 2 & 0.241 \\
\hline & Wbar & 2.0804 & 2 & 0.353 \\
\hline & Wminpv & 1.2416 & 2 & 0.538 \\
\hline & All & 48.775 & 14 & 0 \\
\hline
\end{tabular}


Table 8.3 (continued)

\begin{tabular}{llccc}
\hline Equation & \multicolumn{1}{c}{ Excluded } & chi2 & df & Prob $>$ chi2 \\
\hline Wbar & Employment (youth) & 12.351 & 2 & 0.002 \\
& School (youth) & 1.3399 & 2 & 0.512 \\
& Employment (prime age) & 0.02807 & 2 & 0.986 \\
& Employment (elderly males) & 1.4233 & 2 & 0.491 \\
& Minimum wage & 15.078 & 2 & 0.001 \\
& GDP per capita & 6.485 & 2 & 0.039 \\
& Wminpv & 2.124 & 2 & 0.346 \\
Wminpv & All & 67.719 & 14 & 0 \\
& Employment (youth) & 30.749 & 2 & 0 \\
& School (youth) & 20.214 & 2 & 0 \\
& Employment (prime age) & 24.462 & 2 & 0 \\
& Employment (elderly males) & 0.72476 & 2 & 0.696 \\
& Minimum wage & 24.757 & 2 & 0 \\
& GDP per capita & 3.4185 & 2 & 0.181 \\
& Wbar & 17.809 & 2 & 0
\end{tabular}

Table 8.4 The effects of elderly employment (first difference specification)

Explaining youth employment or unemployment

\begin{tabular}{cccc}
\hline Employment, & Unemployment, & Employment, & Unemployment, \\
OLS & OLS & IV & IV
\end{tabular}
(1)
(2)
(3)
(4)

\begin{tabular}{lcccc}
\hline Emp(elderly males) & 0.591 & -0.557 & 1.140 & -3.039 \\
& $(0.163)^{* * *}$ & $(0.356)$ & $(0.643)$ & $(1.884)$ \\
GDP per capita & $2.54 \mathrm{e}-06$ & -0.0000123 & -0.0000103 & 0.0000435 \\
& $(7.98 \mathrm{e}-06)$ & $(0.0000175)$ & $(0.0000172)$ & $(0.0000503)$ \\
Constant & 0.005 & 0.073 & 0.014 & 0.036 \\
& $(0.005)$ & $(0.011)^{* * *}$ & $(0.012)$ & $(0.034)$ \\
Observations & 32 & 32 & 31 & 31 \\
$R^{2}$ & 0.39 & 0.15 & 0.15 & \\
\hline
\end{tabular}

Note: Standard errors in parentheses.

***Significant at the 1 percent level.

\subsection{Instrumental Variable Specifications}

Table 8.4 presents four regressions. The first two regressions simply regress (first differences of) youth employment and youth unemployment on (first differences of) employment of the elderly, similar to tables 8.1 and 8.2. We include GDP per capita as an additional control variable. The second two regressions use the same specification but now use lagged variables of GDP per capita and of percent twenty to twenty-four in school as instruments. 
We note that the effect of elderly employment on youth employment is significant for ordinary least squares (OLS) and marginally significant for instrumental variables (IV). For youth unemployment we find marginally significant effects. In none of the cases do the signs of the elderly employment variable support the notion that reducing elderly employment will help to improve the chances of younger people in the labor market.

\subsection{Discussion: Employment of the Young and the Inducement to Retire}

In previous phases of the International Social Security (ISS) Project, we have shown that the incentives to retire play an important role in explaining the LFP of the elderly. To check the direct effect of these incentives on the employment and unemployment of the young, we would like to use some average measure of the incentives to retire as explanatory variables for explaining the employment or unemployment of the young. We find that these incentive variables are plausibly Granger caused by youth unemployment, rather than the other way around. This is consistent with a description of the history of labor market policies in the eighties and nineties of the last century.

We do find, however, that both in ordinary regressions and in IV regressions employment of the elderly has a (marginally significant) positive effect on employment of the young and a negative effect on unemployment of the young. This suggests that attempts to improve the labor market perspectives of the young by encouraging the elderly to leave the labor market are likely to be counterproductive (or at least not effective). Altogether, we confirm the suspicion of the originator of the "old for young" idea that the strong increase in early retirement has not had an appreciable positive effect on the employment of the young.

\section{Appendix}

Incentives to retire have been approximated by considering a representative male elderly person who is aged $a$ (between fifty-five and sixty-five), married, and a single earner, who worked at age fifty-four with median earnings but was retired from the labor market in year $t$. Since the person was faced with the decision to retire from the labor force or not from age fifty-five until his actual retirement age, his incentive to retire is calculated as a weighted average of the incentive to retire at the respective ages between fifty-five and $a$, weighted with the proportion of persons still in employment. Next, a weighted average of these incentives (aggregating over all ages $a$ between fifty-five and sixty-five) is calculated where the weights are determined by the respective numbers of retired individuals with age fifty-five, fifty-six, and so 
forth. In these calculations, early retirees are assumed to have been eligible for early retirement; and the disabled are assumed to have been eligible for disability benefits. Thus, the variables used are a weighted average of the incentive to retire via ER and DI, where the weights depend on age and year (since no exact information by year is available for the whole period, the gradual introduction of ER between 1974 and 1984 has been approximated). The incentives have been approximated from 1973 onward (with earliest retirees having retired in 1963; however, since the tax schedule before 1973 is problematic, changes in the tax schedule between 1963 and 1973 have not been taken into account).

The incentive variables that we calculate in this way are wbar - a weighted average of the social security wealth of the retirees in question - as well as Wminpv, social security wealth minus the peak value, the highest obtainable SSW.

\section{References}

Sociale Verzekeringsbank (SVB). 2007. Vijftig Jaar AOW. Available at: http://www .svb.nl.

Van Oorschot, W. 2007. Narrowing pathways to early retirement in the Netherlands. Journal of Poverty and Social Justice 15 (3): 247-55.

Vrijzinnig Protestantse Radio Omroep (VPRO). 2004. Andere Tijden: De geboorte van de VUT. Available at: http://geschiedenis.vpro.nl/programmas/2899536/ afleveringen/19273461/. 